\title{
NOTES
}

\section{THE IDENTITY OF ZYGOSPORIN A AND GYTOGHALASIN D}

\author{
D. C. Aldridge and W. B. Turner \\ Imperial Chemical Industries Ltd., \\ Pharmaceuticals Division, \\ Alderley Park, Macclesfield, \\ Cheshire, U. K.
}

(Received for publication November 29, 1968)

Workers at the Shionogi Research Laboratory have recently reported ${ }^{1)}$ the isolation of zygosporin A, described as "a new antibiotic". They pointed out the similarity between the biological properties of zygosporin $\mathrm{A}$ and those of the cytochalasins ${ }^{2}$, and noted that zygosporin $\mathrm{A}$ is isomeric with cytochalasins $\mathrm{C}$ and $\mathrm{D}^{3)}$. They claim, however, that "the chemical property of zygosporin A was found to differ from those of cytochalasins $\mathrm{C}$ and $\mathrm{D}$ ".

In fact only one chemical reaction of cytochalasin C and none of cytochalasin D has been reported ${ }^{3)}$, and it is quite clear from its published ${ }^{11}$ infrared spectrum and m. p. $\left(268 \sim 270^{\circ} \mathrm{C}\right)$ that zygosporin $\mathrm{A}$ is identical with cytochalasin D, m. p. $267 \sim 271^{\circ} \mathrm{C}$, infrared spectrum shown in Fig. 1 . The full chemical structures of cytochalasins $\mathrm{C}$ and $\mathrm{D}$, which were first reported at a meeting at Sheffield University in September, 1967, are the subject of a paper submitted for publication in the Journal of the Chemical Society ${ }^{4}$.
In view of the similarity between the biological properties and molecular formula of zygosporin A and those of cytochalasins $\mathrm{C}$ and $\mathrm{D}$ it is unfortunate that the Shionogi group did not attempt to compare their compound directly with cytochalasins $\mathrm{C}$ and $\mathrm{D}$ before claiming it as a new compound, with the resulting confusion of nomenclature.

\section{References}

1) Hayakawa, S.; T. Matsushima, T. Kimura, H. Minato \& K. Katagiri : Zygosporin A, a new antibiotic from Zygosporium masonii. J. Antibiotics $21: 523 \sim 524,1968$

2) CARter, S. B. : Effects of cytochalasins on mammalian cells. Nature $213: 261 \sim 264$, 1967

3) Aldridge, D. C.; J. J. Armstrong, R. N. SPeake \& W.B. Turner : The cytochalasins, a new class of biologically active mould metabolites. Chem. Comm. $1: 26 \sim 27,1967$

4) Aldridge, D. C. \& W. B. Turner: The structures of cytochalasins $\mathrm{C}$ and D. J. Chem. Soc. (C), in press.

Added in proof: The structure of zygosporin $\mathrm{A}$, derived by $\mathrm{X}$-ray analysis, has been published* and is identical with the structure derived chemically for cytochalasin $\mathrm{D}^{4)}$.

* Tsukuda, Y.; M. Matsumoto, H. Minato \& H. Koyama : Structure of zygosporin A : X-ray analysis of isozygosporin A p-bromobenzoate. Chem. Comm. 41, 1969

Fig. 1.

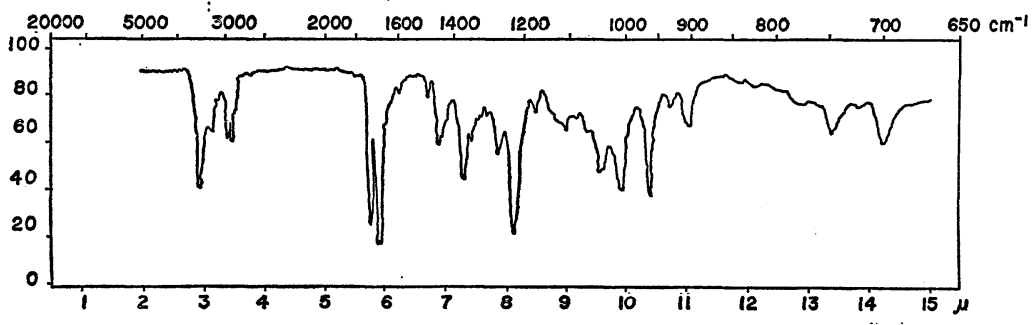

